\title{
Job opportunities in Australia
}

Richard Pearson

\begin{abstract}
For 200 years Australia has looked overseas for labour, attracting emigrants from throughout the world. As the fanfares sound for its bicentenary, does Australia still hold its attraction for job seekers?
\end{abstract}

Australia has not been isolated from world economic trends and it also traditionally suffers from a high level of unemployment, which last year averaged 7.5 per cent, down from a high of 10.5 per cent three years earlier. Australia also suffers from selected skill shortages, experiencing the same paradoxes as many other developed countries: over-supply of lowskilled people and shortages of the more highly skilled. So what are the employment opportunities for the highly qualified would-be emigrant of the late 1980 s?

The Australian economy has recovered well from the recession at the start of the decade; indeed its recession lagged behind the rest of the world, reaching its worst in 1982-83, a year or two behind everyone else. Since then, gross domestic product has risen by 4 or 5 per cent annually, although the rate has now fallen back to nearer 3 per cent. Employment has grown strongly over this period, increasing by over 10 per cent since the recession. This growth did not, however, have a commensurate effect on unemployment because of the continuing growth in the size of the labour force and rising participation rates by women. As in Britain, women have been the main beneficiaries of the growth in jobs in the service sector, particularly for part-time workers.

By 1987, services accounted for two out of three jobs, the balance of employment being taken up by manufacturing and other industry, and agriculture (Fig. 1). The fastest growing sectors this decade have been financial, business and property services, fuelled in part by deregulation of the financial markets, and community and welfare services, and retailing. Between them, these three sectors accounted for two-thirds of the job growth. Manufacturing employment, by contrast, has shown little change overall in recent years after a long period of decline. In the mid-1960s, it accounted for one in five jobs; it is now down to one in six.

In line with international experience, the highly qualified have benefited from this employment growth, with job numbers increasing by 5 per cent annually, and skill shortages are starting to reappear. As a consequence, the number of employerinspired visas for skilled immigrants doubled over the past three years to 3,500 last year.

At an occupational level, the servicebased occupations grew fastest following sectoral growth trends, with health and data-processing leading the way, along with social scientists and skilled service occupations such as motor mechanics and chefs. For scientists, the picture has been mixed. In the physical sciences, where there are about 14,000 professionals, there has been a small surplus. In geoscience and mining-related occupations, a long period of growth came to an end with the recession; but demand has since started picking up again and some regional shortages have been appearing for experienced staff. For chemists, demand generally fluctuates with the economy but currently tends to oversupply, as does demand for physicists, although they are more insu-

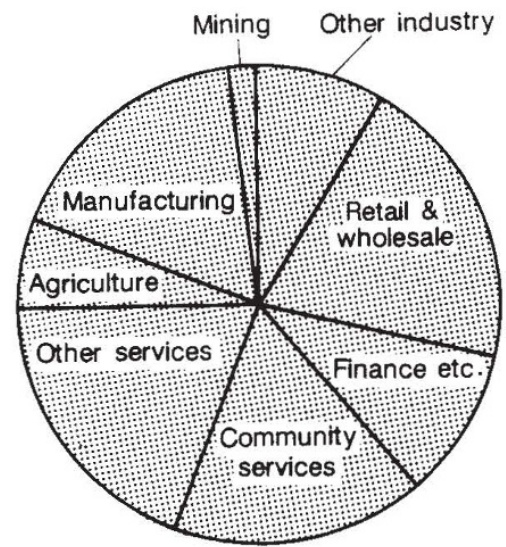

Sectoral employment (source: Labour Force Australia)

lated from economic fluctuations, having a high dependency on the public sector. Life scientists form a similarly sized group, with over half employed in the public sector, research or scientific institutions. As such, their job prospects are heavily dependent on the state, which has been constraining employment growth resulting in generally limited employment opportunities. The one group of scientists in strong demand are the food scientists, who are mainly employed in the private sector, and who have been benefiting from the growth in the fast-food sector and the rising interest in nutrition and diet.

Computer-related occupations once again appear at the top of the list of good employment prospects, demand having risen spectacularly since the early 1970 s. There are now over 25,000 computer programmers and systems analysts in Australia, with more than 500 immigrants entering in each of the past five years. The recession dented the growth in demand but this has turned up again strongly for experienced staff. Finally, there have been mixed fortunes for the 50,000 engineers with job prospects for many being closely linked to the fluctuating fortunes of the mining and construction industries. The new supply of graduate engineers has also fluctuated markedly over the years in response to both perceived market conditions and changing student interests. A downturn in intakes in the 1970 s led to shortages in the early 1980 s. Since then, supply has picked up faster than opportunities leading to difficulties for many new graduates; with a contrasting growth in opportunities, there have been shortages of experienced staff. The strongest demand is for electronics, industrial and civil engineers; the lowest for mechanicals.

The outlook for the skilled labour market generally is one of continuing strong demand for occupations linked to the service sector, most notably computing and health professionals, while prospects for other groups will depend on their sector's economic performance. A further complication in the balance between supply and demand has been the erratic trend in output from training schemes and some undergraduate programmes such as engineering. For example, apprentice intakes in the early 1980 s fell from 49,000 to 35,000 in a two-year period and the effects of this fall will continue to be felt until the end of the decade.

Australia, like almost every other country, now recognizes the need to invest in developing a highly qualified and skilled workforce if it is to be competitive in world markets. The government has therefore embarked on a strategy of improving training prospects for young people, increasing participation in education after the age of 16 to match the records of countries such as the United States and Japan in secondary education, boosting the number of places in higher education, and encouraging closer cooperation between industry and education. The impact on the more immediate shortages of certain types of highly specialized, experienced staff will, however, be only limited. This is where the country's traditional reliance on immigration is likely to help would-be emigrants, provided they have the highly specialist skills needed.

Richard Pearson is at the Institute of Manpower Studies, Mantell Building, University of Sussex, Brighton BNI 9RF, UK. 